MR. JEAN GUY LEBLANC (Orcid ID : 0000-0002-4634-8630)

Article type : Original Article

\title{
Effect of riboflavin-producing bacteria against chemically-induced colitis in mice
}

\section{Running headline: riboflavin producing BAL in colitis}

Romina Levit ${ }^{1}$, Graciela Savoy de Giori ${ }^{1,2}$, Alejandra de Moreno de LeBlanc ${ }^{1}$, Jean Guy LeBlanc $^{1^{*}}$

${ }^{1}$ Centro de Referencia para Lactobacilos (CERELA-CONICET).Chacabuco 145, (T4000ILC) San Miguel de Tucumán, Tucumán, Argentina

${ }^{2}$ Cátedra de Microbiología Superior, Facultad de Bioquímica, Química y Farmacia, Universidad Nacional de Tucumán, San Miguel de Tucumán, Tucumán, Argentina

*Corresponding author

Dr. Jean Guy LeBlanc

CERELA-CONICET

Chacabuco 145, San Miguel de Tucumán, Tucumán (T4000ILC), Argentina

E-mail: leblanc@cerela.org.ar / leblancjeanguy@gmail.com

Tel/Fax.: +54 (381) 4310465.

\section{Abstract}

Aim. To assess the anti-inflammatory effect associated to individual probiotic suspensions of riboflavin-producing lactic acid bacteria (LAB) in a colitis murine model.

Methods and Results. Mice intrarectally inoculated with trinitrobenzene sulfonic acid (TNBS) were orally administered with individual suspensions of riboflavin-producing strains: Lactobacillus (Lact.) plantarum CRL2130, Lact. paracasei CRL76, Lact. bulgaricus CRL871, Streptococcus thermophilus CRL803; a non riboflavin-producing strain or commercial riboflavin. The extent of colonic damage and inflammation and microbial translocation to liver were evaluated. iNOs enzyme was analyzed in the intestinal tissues and cytokine concentrations in the intestinal fluids. Animals given either one of the four riboflavinproducing strains showed lower macroscopic and histologic damage scores, lower microbial translocation to liver, significant decreases of iNOs+ cells in their large intestines and

This article has been accepted for publication and undergone full peer review but has not been through the copyediting, typesetting, pagination and proofreading process, which may lead to differences between this version and the Version of Record. Please cite this article as doi: 10.1111/jam.13622

This article is protected by copyright. All rights reserved. 
decreased pro-inflammatory cytokines, compared to mice without treatment. The administration of pure riboflavin showed similar benefits. Lact. paracasei CRL76 accompanied its anti-inflammatory effect with increased IL-10 levels demonstrating other beneficial properties in addition to the vitamin production.

Conclusion. Administration of riboflavin-producing strains prevented the intestinal damage induced by TNBS in mice.

Significance and impact of the study. Riboflavin-producing phenotype in $L A B$ represents a potent tool to select them for preventing/ treating IBD.

Keywords: riboflavin, colitis, lactic acid bacteria, probiotic, anti-inflammatory effect

\section{Introduction}

Inflammatory bowel diseases (IBD) are a group of chronic disorders characterized by inflammation of the gastrointestinal tract. Crohn's disease (CD) and ulcerative colitis (UC), the two main manifestations of IBD, exhibit common and distinct clinical and pathological characteristics (Espaillat et al. 2016). The pathogenesis of IBD is still unclear but they are defined as multifactorial diseases with genetic, immunological, environmental and microbial factors related to their development (Siczek et al. 2016). IBD have become global diseases with high incidence rates that affect the quality of life of patients and also increase their risk of colon cancer development (Chen et al. 2016). Current therapies for against IBD are limited by high costs, high toxicities and undesirable side effects (de Souza Araújo et al. 2016; Wang et al. 2017). This emphasizes the need to search for novel therapeutic options.

Accumulated data indicate that probiotic supplementation promotes beneficial effects in intestinal diseases such as IBD (LeBlanc and De Moreno de LeBlanc 2016). Probiotics are defined as "live microorganisms, which when administered in adequate amounts confer a beneficial health effect on the host" (FAO/WHO, 2001) (FAO/WHO 2001). Among probiotics, certain strains of lactic acid bacteria (LAB) have been shown to exert beneficial effects against IBD via different mechanisms, including the modulation of the intestinal microbiota and the alteration of their metabolic properties (de Moreno de LeBlanc and LeBlanc 2014), the reduction of oxidative stress (del Carmen et al. 2014) and the improvement of the host's immune response (Ferreira dos Santos et al. 2016). In addition, some LAB have also been reported to have the capacity to produce antioxidant vitamins such as riboflavin (vitamin B2) (Burgess et al. 2006; LeBlanc et al. 2011b; Capozzi et al. 2012). Recently, our group demonstrated the anti-inflammatory effect of soymilk fermented by the riboflavinproducing strain Lactobacillus (Lact.) plantarum CRL2130 in a murine model of colitis (Levit et al. 2017). The comparison with a related strain without the capacity to produce vitamin B2 and also with the supplementation of commercial vitamin allowed demonstrating that in addition of the mechanisms mentioned above, the bioproduction of certain vitamins such as riboflavin could be a new tool of probiotic LAB against IBD.

This article is protected by copyright. All rights reserved. 
In the present study we evaluated the anti-inflammatory effect associated to the administration of riboflavin-producing $L A B$ as individual probiotic suspensions (not in a food matrix). Therefore, the aim of this work was to assess i) the anti-inflammatory effect associated to individual probiotic suspensions and ii) the species/strain dependent character of this anti-inflammatory effect using a colitis murine model.

\section{Methods}

\section{Bacterial strains and growth conditions}

Five strains of LAB belonging to the Culture collection of CERELA (Centro de Referencia para Lactobacilos, CONICET, San Miguel de Tucumán, Argentina) were used in this study. Four strains used were selected due to their riboflavin-producing capabilities as shown in previous studies (Juarez del Valle et al. 2014): Lac. plantarum CRL2130, Lact. paracasei CRL76, Lact. delbrueckii subsp. bulgaricus CRL871, Streptococcus (Strep.) thermophilus CRL803. Lact. plantarum CRL2130 is a riboflavin over-producing strain selected after exposure to increasing concentrations of roseoflavin, a structural analog of riboflavin. Lact. plantarum CRL691 was used as a non-riboflavin producing strain (negative control). Bacteria were grown for $16 \mathrm{~h}$ at $37^{\circ} \mathrm{C}$ without agitation in $5 \mathrm{ml}$ of Man, Rogose Sharpe (MRS, Britania, Buenos Aires, Argentina) for lactobacilli or LAPTg containing (w/v) 1,5\% peptone, $1 \%$ tryptone, $1 \%$ yeast extract, $1 \%$ glucose and $0,1 \%$ Tween 80 for streptococci. After activation, riboflavin-producing LAB were used to inoculate at $4 \%(\mathrm{v} / \mathrm{v}) 10 \mathrm{~mL}$ of riboflavin-free culture medium (Riboflavin Assay Medium, Difco, Becton, Dickinson, and Co., Sparks, Maryland) and then incubated without agitation at $37^{\circ} \mathrm{C}$ for $16 \mathrm{~h}$.

\section{Preparation of probiotic suspensions and vitamin B2 solution}

After growth in the riboflavin-free culture medium or MRS (for Lact. plantarum CRL691), LAB cultures were washed with sterile saline solution $(0,85 \% \mathrm{~m} / \mathrm{v} \mathrm{NaCl})$ and resuspended in $1 \mathrm{ml}$ of this solution with the aim of concentrating 10 times. The final concentrations of bacteria for animal feeding were $5 \pm 3 \times 10^{8}$ colony forming units per $\mathrm{ml}$ and $100 \mu \mathrm{l}$ were given to each mouse on a daily basis as described below.

A pure riboflavin solution ( $40 \mu \mathrm{g} \mathrm{ml}^{-1}$ ) was also prepared to administer to the animals as a control. Considering that Lact. plantarum CRL2130 is the strain under study that produces the highest concentration of riboflavin (capable of producing $1.6 \mu \mathrm{g} \mathrm{ml}^{-1}$ of this vitamin in soymilk (Juarez del Valle et al. 2014)) and taking into account that the anti-inflammatory effect of the fermented beverage was observed when the mice consumed $3 \mathrm{ml}$ per day (Levit et al. 2017), the mice in the present study require to consume approximately $4 \mu \mathrm{g}$ of this vitamin per day to have a comparable amount of riboflavin than those that consume the highest producing strain.

\section{Animals}

Female BALB/c mice (six week, $n=52$ ) were obtained from the inbred closed colony maintained at CERELA. Animals were housed under protocols approved by the Animal

This article is protected by copyright. All rights reserved. 
Protection Committee of CERELA (CRL-BIOT-LT-2010/1A) and all experiments comply with the current laws of Argentina and international organizations for the use of experimental animals. The room was at $18-20{ }^{\circ} \mathrm{C}$ and $20 \%$ humidity under a $12 \mathrm{~h}$ light/dark cycle. The animals were fed with commercial riboflavin-free diet (Dyets, USA) (to avoid the interference of riboflavin from balanced rodent diets) and water ad libitum throughout the study.

\section{Induction of colitis and treatments}

Acute colitis was induced in mice by intrarectal injection of trinitrobenzene sulfonic acid (TNBS, Sigma, St. Louis, MO) as has been described previously (Levit et al. 2017). The control group (mock group) was treated with ethanol-PBS mixture instead of TNBS.

Mice were divided into eight groups. Animals were orally administered with $100 \mu$ of saline solution (mock and TNBS + Saline groups), individual suspension of one of the riboflavinproducing strains (TNBS + CRL2130, TNBS + CRL76, TNBS + CRL871 and TNBS + CRL803 groups), the non riboflavin-producing strain (TNBS + CRL691 group) or riboflavin solution (TNBS + B2 group) using a gavage syringe once a day during five days. Figure 1 shows a scheme of experimental protocol with the samples obtained for the different assays.

\section{Macroscopic and histological evaluation of colon damage}

Evaluation of macroscopic damage in colon was performed according to previously established scoring system on a 0-9 scale, by two independent observers. In this system, the presence of each parameter (erythema, hemorrhage, edema, stricture formation, ulceration, fecal blood, presence of mucus, diarrhea and adhesions) adds one point (Cenac et al. 2002).

Fixed colons were embedded in paraffin; $5-\mu \mathrm{m}$ paraffin sections were cut, stained with hematoxylin and eosin (H\&E) and observed under a light microscopy for histological examination, or used for immunofluorescence analysis. The histologic damage (Table 1) was evaluated using a histopathological score described previously (Ameho et al. 1997).

\section{Bacterial translocation to liver}

Livers were homogenized in peptone solution and serial dilutions of the homogenates were plated in triplicate into the following media: MRS agar, MacConkey agar (both from Britania, Buenos Aires, Argentina) and LAPTg agar (1\% glucose, 1.5\% peptone, 1\% tryptone, 1\% yeast extract and $0.1 \%$ Tween 80 ). The plates were incubated at $37^{\circ} \mathrm{C}$ and the number of bacterial colonies was recorded after 48 - $72 \mathrm{~h}$.

\section{Measurment of iNOs (inducible Nitric Oxyde Synthase) producing cells}

The number of iNOs+ cells was determined by indirect immunofluorescence on large intestine tissue slides following the technique describe previously (de Moreno de LeBlanc et al. 2004). Rabbit anti-iNOs polyclonal antibody (Zymed Laboratories Inc., San Francisco, California, USA) was used as primary antibody and goat anti-rabbit antibody conjugated

This article is protected by copyright. All rights reserved. 
with FITC (Jackson Immuno Research, Labs. Inc., West Grove USA) as secondary. Fluorescent cells were counted by two different scientists in thirty fields of vision at $1000 x$ of magnification using a fluorescence light microscope. The results were expressed as the number of positive cells in ten fields of vision. The group of mice that received the non riboflavin- producing strain was not included because significant differences with the inflamed control were not observed when the other parameters of inflammation were analysed.

\section{Determination of cytokines in the intestinal contents}

Luminal contents of colons were centrifuged ( $3000 \mathrm{xg}, 10 \mathrm{~min}, 4 \mathrm{O} \mathrm{C})$, and the supernatants were stored at $-80 \circ \mathrm{C}$ until cytokines determinations. Cytometric Bead Array (CBA) mouse inflammation kit (BD Bioscience, San Diego, CA, USA) was used to measure Interleukin-10 (IL-10), IL-17, Tumor Necrosis Factor (TNF- $\alpha$ ), Interferon $\gamma$ (IFN- $\gamma$ ), IL-6, IL-4 and IL-2 levels, following the manufacturer's instructions. Results were expressed as pg of cytokine per mg of protein in the colon contents. The group of mice that received the non riboflavinproducing strain was not included in this determination because the same reason explained for iNOS+ cells determination.

\section{Statistical analysis}

Statistical analyses were performed by MINITAB 15 software (Minitab, State College, PA, USA) using ANOVA general linear model, followed by Tukey's post hoc test and $p<0.05$ was considered as statically significant. All data were expressed as the mean \pm standard deviation (SD).

\section{Results}

\section{Macroscopic and histologic evaluation of colons}

The intrarectal injection of TNBS caused severe intestinal inflammation in mice characterized by high values of macroscopic and histological damage scores in the large intestines (Fig. 2a). Macroscopically, most of mice from TNBS + Saline group showed erythema, hemorrhage, ulcerations, fecal blood and adhesions. Similar damages have been observed in mice that received Lact. plantarum CRL691. The administration of riboflavinproducing bacteria or the commercial vitamin reduced the macroscopic damages where only some mice showed ulceration, presence of mucus and / or diarrhea and most had intestines similar to the mock group (Fig. 2b). The results of H\&E staining (Fig. 2c) showed prominent inflammatory cell infiltration in the mucosa and submucosa, crypt lesions, and loss of the goblet cells in animals from TNBS + Saline and TNBS + CRL691 groups, compared to the colons of animals from mock group. The severity of inflammation was significantly lower $(p<0.05)$ in most of the riboflavin-producing bacteria administered groups (TNBS + CRL2130, TNBS + CRL76, TNBS + CRL871 groups) compared to TNBS + Saline group. Most of mice presented inflammatory infiltrate (admixture of neutrophils) in mucosal and / or submucosal, but these changes involved small areas of the samples; only few animals

This article is protected by copyright. All rights reserved. 
showed prominent infiltrates (with predominance of neutrophils) involving deeper areas. The administration of commercial riboflavin showed beneficial effects similar to those observed with the vitamin producing bacteria.

\section{Bacterial translocation}

The intestinal damage observed in the macroscopic and histological analysis was confirmed with the microbial translocation assay. As shown in Fig. 3, compared with the mock group, the microbial counts in liver were significantly $(p<0.05)$ higher in TNBS + Saline group. Mice given the non-riboflavin producing strain (TNBS + CRL691 group) did not show significantly different microbial counts compared to the TNBS + Saline group. The presence of microorganisms in the liver of mice from mock group is attributed to the slight inflammation caused by the ethanol; so these values have been taken as a baseline for the comparisons with the other groups. The number of colony forming units was reduced significantly $(p<$ 0.05 ) when the mice received either one of the four riboflavin-producing strains (TNBS + CRL2130, TNBS + CRL76, TNBS + CRL871 and TNBS + CRL803 groups) as well as in those animals that received the commercial vitamin (TNBS + B2 group), compared to TNBS + Saline group.

\section{iNOs+ cells in the large intestinal tissues}

The evaluation of the iNOS+ cells in the colon tissues were performed in the groups that received the riboflavin-producing strains in comparison with the mock group and with the mice from TNBS + Saline and TNBS + B2 groups. As shown in Fig. 4, it was found that TNBS inoculation resulted in significantly $(p<0.05)$ elevated number of iNOs+ cells in intestinal tissues of mice from TNBS + Saline group compared to mock group. Furthermore, values of iNOs+ cells were significantly $(p<0.05)$ lower in the intestines of animals that received treatment with the riboflavin-producing strains (TNBS + CRL2130, TNBS + CRL76, TNBS + CRL871 and TNBS + CRL803 groups) in relation with TNBS + Saline group. For commercial riboflavin treated mice (TNBS + B2 group) similar values for iNOs+ cells as when the bacteria were administered were observed in the intestinal tissues. The group given the riboflavin over-producing strain (TNBS + CRL2130) was the only one that reached values similar to mock group $(p>0.05)$.

\section{Cytokine levels in intestinal fluids}

The assessment of the cytokines concentrations was performed in the same groups detailed for iNOS evaluation. As depicted in Fig. 5, TNBS instillation leads the mice from TNBS + Saline group to significantly increase $(p<0.05)$ the levels of pro-inflammatory cytokines TNF- $\alpha$, IL-17, IFN- $\gamma$ and IL- 6 in the intestinal fluids compared with the mock group. The antiinflammatory cytokine IL-10 was maintained with similar values in both TNBS + Saline and mock groups. In contrast, a significant $(p<0.05)$ decrease was observed in the levels of proinflammatory cytokines in the intestinal contents of TNBS + CRL2130, TNBS + CRL871 and TNBS + B2 groups compared with animals from TNBS + Saline group. TNBS + CRL803 group

This article is protected by copyright. All rights reserved. 
showed significant decreased levels only for some pro-inflammatory cytokines. Mice from TNBS + CRL76 group showed an increase for IL-10 concentrations compared to the other test groups, accompanied by decreased levels of pro-inflammatory cytokines, compared to TNBS + Saline group.

\section{Discussion}

Pathogenesis of IBD is not yet fully understood; however, several studies have demonstrated that increased production of inflammatory mediators including eicosanoids, cytokines, chemokines and reactive oxygen species (ROS) are implicated in this process (de Souza Araújo et al. 2016). The overproduction of ROS can lead to an imbalance among these oxidant molecules and the antioxidant defense system, predisposing the patients to intestinal tissue destruction and the development of IBD (Ji et al. 2015). So, anti-oxidant agents, such as some vitamins, have been associated to beneficial effects against IBD, both in animal models and in human reports (Moura et al. 2015) (Selhub et al. 2013).

The use of probiotic microorganisms have been proposed as an alternative for IBD patients due to numerous beneficial effects, including but not limited to the modulation of the immune system and the restoration of intestinal microbial balance. Probiotic LAB strains expressing high levels of antioxidant enzymes have been explored as a tool to combat oxidative stress, giving rise to potential applications for IBD treatment (LeBlanc et al. 2011a). It was also demonstrated that Strep. thermophilus CRL807 with intrinsic immunomodulatory properties and genetically engineering to express antioxidant enzymes (CAT and SOD), enhanced its anti-inflammatory activity and diminished the severity of inflammation in a mouse model of colitis (del Carmen et al. 2014).

In addition to above mentioned mechanisms, certain strains of LAB have also been shown to have the capacity to produce antioxidant vitamins such as riboflavin. The antioxidant nature of riboflavin, both by itself and as part of the glutathione reductase and xhantine oxidase systems is well known. Studies confirmed the role of this vitamin in protecting the body against oxidative stress (Thakur et al. 2016). Recently, our group has reported the antiinflammatory potential of soymilk fermented by the riboflavin overproducing Lact. plantarum CRL2130 in a TNBS- induced colitis mice model (Levit et al. 2017). This was the first study demonstrating the beneficial effect of a riboflavin-producing strain in an intestinal inflammation animal model. At difference, the parenteral related strain (the same evaluated in the present work), without the capacity to produce the vitamin did not show benefits in the inflamed mice. In function of these results, the aim of the present work was to improve the proposal of riboflavin- overproducing phenotype as a possible part of the probiotic phenotype of LAB selected for their anti-inflammatory / anti-oxidant properties (Parvez et al. 2006; Sleator and Hill 2008; Arena et al. 2014).The use of bacterial suspensions instead of a fermented food for the protocol of riboflavin-producing bacteria administration was specially analyzed to facilitate the potential uses of these strains in patients suffering

This article is protected by copyright. All rights reserved. 
IBD. The assays demonstrated that all the riboflavin-producing strains tested in the IBD model decreased the severity of inflammation with lower macroscopic and histologic intestinal damage scores, and a decrease in bacterial translocation to liver compared to TNBS control group. The anti-inflammatory effect obtained when the riboflavin-producing Lact. plantarum CRL2130 was administered in a food matrix was maintained with the protocol of administration used in the present work (Levit et al. 2017). Alleviation of inflammation has also been noted by reduced levels of pro- inflammatory cytokines in the intestinal fluids from mice that received either one of the four riboflavin producing strains, similar to the effect observed when the commercial riboflavin was administered. This effect was also associated to significant decrease of iNOS expression in the intestinal tissues, compared to inflamed control group, by being the lowest values (without significant differences with the mock group) observed in the mice that received the riboflavin overproducing strain (Lact. plantarum CRL2130). The pathological role of increased nitric oxide (NO) production and iNOS expression has been suggested in models of experimental colitis (Khelifi et al. 2017) and also by analyzing samples from humans suffering IBD (Guihot et al. 2000; Dhillon et al. 2014) since many years ago. The administration of Lact. paracasei CRL76 to mice was accompanied by an immunomodulatory effect evidenced by increased production of IL-10. For this strain, other mechanisms, in addition to riboflavin production, would be involved. These differences were also observed in vitro by analyzing the production of NO by LPS stimulated macrophages when they were co-cultured with the LAB. All riboflavin-producing LAB under study had an anti-inflammatory effect; however, Lact. paracasei CRL76 showed the lowest production of NO in this system, even lower than the commercial vitamin (data not shown). Our studies are supported by anti-inflammatory properties associated to riboflavin. It was previously reported that riboflavin treatment was capable to reduce TNF- $\alpha$ release from blood leukocytes in addition to improving levels of antioxidant parameters (reduced glutathione and malondialdehyde) in rats with $\mathrm{CCl}_{4}{ }^{-}$ induced hepatic injury (Al-Harbi et al. 2014).

In agreement with our results another study has reported the beneficial effect of vitaminproducing LAB (Lact. plantarum 156, Lact. brevis 165 and Lact. rhamnosus 195) isolated from fecal samples of healthy humans in Iran. These strains were identified as vitamin B12 producers and additionally have showed an anti-inflammatory effect in a mouse colitis model (Rohani et al. 2015).

Our data indicates that the administration of riboflavin-producing strains can prevent acute mice colitis induced by TNBS similar to the use of the commercial vitamin. The antiinflammatory effect observed could be attributed, at least partially, to the antioxidant actions of riboflavin, which alleviates chemically induced colitis in mice by ameliorating oxidative stress. However the antioxidant activity of the tested strains was not assayed indicating the need for further studies. In addition to vitamin production, other immunomodulatory properties were observed for Lact. paracasei CRL76 and open the

This article is protected by copyright. All rights reserved. 
potential to study this strain in other models associated to inflammation. It is also important to mention that the beneficial effect observed when riboflavin-producing LAB were administered as a bacterial suspension are in accordance with previous results obtained when the strains were given in a food matrix (soymilk), suggesting that they could be included in a pharmaceutical formulation. We also maintain the opportunity to test our hypothesis with a major number of strains or biofortified matrices described by other authors (Capozzi et al. 2011; Russo et al. 2014; Puertas et al. 2016; Chandrasekar Rajendran et al. 2017).

In conclusion, the present work provides in vivo evidence that oral administration of riboflavin-producing LAB can prevent TNBS-induced colitis in mice similar to the use of the commercial pure vitamin, which indicates that this phenotype in probiotic LAB may represent a potent tool, as an alternative or as a complement to current therapies, for preventing and treating IBD.

\section{Acknowledgments}

The authors would like to thanks Consejo Nacional de Investigaciones Científicas y Técnicas (CONICET) and Agencia Nacional de Promoción Científica y Tecnológica (ANPCyT) for the financial support. This work was financially supported by CONICET, (projects PIP006 and 0697) and ANPCyT (projects 3045, 2554 and 2859).

Conflicts of interest: The authors declare that there are no conflicts of interest.

\section{References}

Al-Harbi, N.O., Imam, F., Nadeem, A., Al-Harbi, M.M., Iqbal, M. and Ahmad, S.F. (2014)

Carbon tetrachloride-induced hepatotoxicity in rat is reversed by treatment with riboflavin. Int Immunopharmacol 21, 383-388.

Ameho, C.K., Adjei, A.A., Harrison, E.K., Takeshita, K., Morioka, T., Arakaki, Y., Ito, E., Suzuki, I., Kulkarni, A.D. and Kawajiri, A. (1997) Prophylactic effect of dietary glutamine supplementation on interleukin 8 and tumour necrosis factor $\alpha$ production in trinitrobenzene sulphonic acid induced colitis. Gut 41, 487-493.

Arena, M.P., Russo, P., Capozzi, V., Lopez, P., Fiocco, D. and Spano, G. (2014) Probiotic abilities of riboflavin-overproducing Lactobacillus strains: a novel promising application of probiotics. Appl Microbiol Biotechnol 98, 7569-7581.

Burgess, C.M., Smid, E.J., Rutten, G. and Van Sinderen, D. (2006) A general method for selection of riboflavin-overproducing food grade micro-organisms. Microb Cell Fact 5, 1. Capozzi, V., Menga, V., Digesu, A.M., De Vita, P., van Sinderen, D., Cattivelli, L., Fares, C. and Spano, G. (2011) Biotechnological production of vitamin B2-enriched bread and pasta. J Agric Food Chem 59, 8013-8020.

Capozzi, V., Russo, P., Dueñas, M.T., López, P. and Spano, G. (2012) Lactic acid bacteria producing B-group vitamins: a great potential for functional cereals products. App Microbiol Biotechnol 96, 1383-1394.

Cenac, N., Coelho, A.-M., Nguyen, C., Compton, S., Andrade-Gordon, P., MacNaughton, W.K., Wallace, J.L., Hollenberg, M.D., Bunnett, N.W. and Garcia-Villar, R. (2002) Induction of

This article is protected by copyright. All rights reserved. 
intestinal inflammation in mouse by activation of proteinase-activated receptor-2. Am J Pathol 161, 1903-1915.

Chandrasekar Rajendran, S.C., Chamlagain, B., Kariluoto, S., Piironen, V. and Saris, P.E.J. (2017) Biofortification of riboflavin and folate in idli batter, based on fermented cereal and pulse, by Lactococcus lactis N8 and Saccharomyces boulardii SAA655. J Appl Microbiol 122, 1663-1671.

Chen, Y.Y., Li, R.Y., Shi, M.J., Zhao, Y.X., Yan, Y., Xu, X.X., Zhang, M., Zhao, X.T. and Zhang, Y.B. (2016) Demethyleneberberine alleviates inflammatory bowel disease in mice through regulating NF-kappaB signaling and T-helper cell homeostasis. Inflamm Res 66, 187-196. de Moreno de LeBlanc, A. and LeBlanc, J.G. (2014) Effect of probiotic administration on the intestinal microbiota, current knowledge and potential applications. World J Gastroenterol 20, 16518-16528.

de Moreno de LeBlanc, A., Valdez, J. and Perdigón, G. (2004) Inflammatory immune response. Eur J Inflamm, 2, 21-31.

de Souza Araújo, D.F., Guerra, G.C.B., de Araújo Júnior, R.F., de Araújo, A.A., de Assis, P.O.A., de Medeiros, A.N., de Sousa, Y.R.F., Pintado, M.M.E., Gálvez, J. and do Egypto, R.d.C.R. (2016) Goat whey ameliorates intestinal inflammation on acetic acid-induced colitis in rats. $J$ Dairy Sci 99, 9383-9394.

del Carmen, S., de LeBlanc, A.d.M., Martin, R., Chain, F., Langella, P., Bermúdez-Humarán, L.G. and LeBlanc, J.G. (2014) Genetically engineered immunomodulatory Streptococcus thermophilus strains producing antioxidant enzymes exhibit enhanced anti-inflammatory activities. Appl Environ Microbiol 80, 869-877.

Dhillon, S.S., Mastropaolo, L.A., Murchie, R., Griffiths, C., Thoni, C., Elkadri, A., Xu, W., Mack, A., Walters, T., Guo, C., Mack, D., Huynh, H., Baksh, S., Silverberg, M.S., Brumell, J.H., Snapper, S.B. and Muise, A.M. (2014) Higher activity of the inducible nitric oxide synthase contributes to very early onset inflammatory bowel disease. Clin Transl Gastroenterol 5, e46.

Espaillat, M.P., Kew, R.R. and Obeid, L.M. (2016) Sphingolipids in neutrophil function and inflammatory responses: Mechanisms and implications for intestinal immunity and inflammation in ulcerative colitis. Adv Biol Regul 63, 140-155.

FAO/WHO (2001) Evaluation of health and nutritional properties of powder milk and live lactic acid bacteria. Food and Agriculture Organization of the United Nations and World Health Organization Expert Consultation Report Available from http://www.fao.org/3/aa0512e.pdf

Ferreira dos Santos, T., Alves Melo, T., Almeida, M.E., Passos Rezende, R. and Romano, C.C. (2016) Immunomodulatory Effects of Lactobacillus plantarum Lp62 on Intestinal Epithelial and Mononuclear Cells. BioMed Res Int 2016.

Guihot, G., Guimbaud, R., Bertrand, V., Narcy-Lambare, B., Couturier, D., Duee, P.H., Chaussade, S. and Blachier, F. (2000) Inducible nitric oxide synthase activity in colon biopsies from inflammatory areas: correlation with inflammation intensity in patients with ulcerative colitis but not with Crohn's disease. Amino Acids 18, 229-237.

Ji, K., Jang, N.Y. and Kim, Y.T. (2015) Isolation of Lactic Acid Bacteria Showing Antioxidative and Probiotic Activities from Kimchi and Infant Feces. J Microbiol Biotechnol 25, 1568-1577. Juarez del Valle, M., Laiño, J.E., de Giori, G.S. and LeBlanc, J.G. (2014) Riboflavin producing lactic acid bacteria as a biotechnological strategy to obtain bio-enriched soymilk. Food Res Int 62, 1015-1019.

Khelifi, L., Soufli, I., Labsi, M. and Touil-Boukoffa, C. (2017) Immune-protective effect of

This article is protected by copyright. All rights reserved. 
echinococcosis on colitis experimental model is dependent of down regulation of TNF-alpha and NO production. Acta Trop 166, 7-15.

LeBlanc, J.G. and De Moreno de LeBlanc, A. (2016) Probiotics in Inflammatory Bowel Diseases and Cancer Prevention. In Bioactive Foods in Health Promotion: Probiotics, Prebiotics, and Synbiotics ed. Elsevier, A.P. pp.755-771. Oxford, UK.

LeBlanc, J.G., Del Carmen, S., Miyoshi, A., Azevedo, V., Sesma, F., Langella, P., BermúdezHumarán, L.G., Watterlot, L., Perdigon, G. and De LeBlanc, A.D.M. (2011a) Use of superoxide dismutase and catalase producing lactic acid bacteria in TNBS induced Crohn's disease in mice. J Biotechnology 151, 287-293.

LeBlanc, J.G., Laiño, J.E., del Valle, M.J., Vannini, V., van Sinderen, D., Taranto, M.P., de Valdez, G.F., de Giori, G.S. and Sesma, F. (2011b) B-group vitamin production by lactic acid bacteria--current knowledge and potential applications. J Appl Microbiol 111, 1297-1309. Levit, R., de Giori, G.S., de Moreno de LeBlanc, A. and LeBlanc, J.G. (2017) Evaluation of the effect of soymilk fermented by a riboflavin-producing Lactobacillus plantarum strain in a murine model of colitis. Benef Microbes 8, 65-72.

Moura, F.A., de Andrade, K.Q., Dos Santos, J.C., Araujo, O.R. and Goulart, M.O. (2015) Antioxidant therapy for treatment of inflammatory bowel disease: Does it work? Redox Biol 6, 617-639.

Parvez, S., Malik, K.A., Ah Kang, S. and Kim, H.Y. (2006) Probiotics and their fermented food products are beneficial for health. J Appl Microbiol 100, 1171-1185.

Puertas, A.I., Capozzi, V., Llamas, M.G., Lopez, P., Lamontanara, A., Orru, L., Russo, P., Spano, G. and Duenas, M.T. (2016) Draft Genome Sequence of Lactobacillus collinoides CUPV237, an Exopolysaccharide and Riboflavin Producer Isolated from Cider. Genome Announc 4.

Rohani, M., Noohi, N., Talebi, M., Katouli, M. and Pourshafie, M.R. (2015) Highly Heterogeneous Probiotic Lactobacillus Species in Healthy Iranians with Low Functional Activities. PloS one 10, e0144467.

Russo, P., Capozzi, V., Arena, M.P., Spadaccino, G., Duenas, M.T., Lopez, P., Fiocco, D. and Spano, G. (2014) Riboflavin-overproducing strains of Lactobacillus fermentum for riboflavinenriched bread. Appl Microbiol Biotechnol 98, 3691-3700.

Selhub, J., Byun, A., Liu, Z., Mason, J.B., Bronson, R.T. and Crott, J.W. (2013) Dietary vitamin $B 6$ intake modulates colonic inflammation in the IL10-/- model of inflammatory bowel disease. J Nutr Biochem 24, 2138-2143.

Siczek, K., Zatorski, H., Chmielowiec-Korzeniowska, A., Pulit-Prociak, J., Smiech, M., Kordek, R., Tymczyna, L., Banach, M. and Fichna, J. (2016) Synthesis and evaluation of antiinflammatory properties of silver nanoparticle suspensions in experimental colitis in mice. Chem Biol Drug Des 89, 538-547.

Sleator, R.D. and Hill, C. (2008) New frontiers in probiotic research. Lett Appl Microbiol 46, 143-147.

Thakur, K., Tomar, S.K., Singh, A.K., Mandal, S. and Arora, S. (2016) Riboflavin and health: A review of recent human research. Crit Rev Food Sci Nutr 57, 3650- 3660.

Wang, H., Gu, J., Hou, X., Chen, J., Yang, N., Liu, Y., Wang, G., Du, M., Qiu, H. and Luo, Y. (2017) Anti-inflammatory effect of miltirone on inflammatory bowel disease via TLR4/NFKB/IQGAP2 signaling pathway. Biomed Pharmacother 85, 531-540.

This article is protected by copyright. All rights reserved. 
Table 1. Histologic score of colon damage

Microscopic findings

Grade

Intestinal histology identical to normal mice

Inflammatory infiltrate (admixture of neutrophils) in mild mucosal

and/or submucosal and edema, punctuate mucosal erosions, muscularis

mucosa intact

Grade 1 changes involving 50\% of the sepcimen

Prominent inflammatory infiltrate and edema (predominance of

neutrophils) with deeper areas of ulceration extending through the

muscularis mucosae into the sub mucosa; inflammatory cells invading

the muscularis propria but without muscle necrosis

Grade 3 changes involving $50 \%$ of the specimen

Extensive ulceration with coagulative necrosis that extends deep into

the muscularis propria

Grade 5 changes involving $50 \%$ of the specimen

Figure legends

Fig. 1. Schematic representation of the protocol used for the colitis model. Colitis was induced by intrarrectal administration of TNBS solution. One day before the TNBS instillation different individual LAB suspensions, commercial riboflavin or saline were intragastrically administrated to mice and this administration continued during four days more. On de fifth day of the experiment mice were euthanized, liver and large intestine were extracted to further analysis described in the scheme.

Fig. 2.Effects of riboflavin-producing $L A B$ on intestinal damages in mice with TNBS-induced colitis. Macroscopic (black bars) and microscopic (grey bars) damage score correspond to samples taken 5 days post TNBS (a). The results were obtained from two independent experiments with 7 mice per group (except for mock group $n=3$ ). For macroscopic observation the score correspond to the addition of each finding associated to the damage. For microscopic score, each value correspond to the grade of damage described in M\&M. * $p<0.05$ compared with mock group; \# $p<0.05$ compared with TNBS + Saline group. Representative photographs of large intestine for each group were selected (b). Representative microscopy images for each group obtained with a magnification of 50X are showed (c).

This article is protected by copyright. All rights reserved. 
Fig. 3.Effects of riboflavin-producing $L A B$ on microbial translocation to liver in mice with TNBS-induced colitis. Microbial growth in MacConkey, MRS or LAPTg of liver samples obtained from different groups were evaluated: mock (black), TNBS+ Saline (white), TNBS+ CRL691 (light grey), TNBS+ CRL2130 (white with diagonal lines), TNBS+CRL76 (dark grey), TNBS+ CRL871 (dotted white), TNBS+ CRL803 (white with horizontal lines) and TNBS+ B2 (dotted black). Values are represented as the mean ( $n=7$, except for the mock group $n=3) \pm$ SD of the log CFU g ${ }^{-1}$ liver. \# $\mathrm{p}<0.05$ compared with TNBS + Saline group.

Fig. 4.Effects of riboflavin-producing LAB on the number of iNOs+ cells in mice with TNBSinduced colitis. The results are expressed as the mean of the number of iNOs positive cells counted in ten fields by two independent scientists at 1000x of magnification (a). The values are the means of 7 mice from each group \pm SD (except for mock group that had 3 mice). Data with a different letter ( $a-d)$ statistically differ $(p<0.05)$. Mock (black), TNBS+ Saline (white),TNBS+ CRL2130 (white with diagonal lines), TNBS+CRL76 (dark grey), TNBS+ CRL871 (dotted white), TNBS+ CRL803 (white with horizontal lines) and TNBS+ B2 (dotted black). Representative images of immunofluorescence assay of large intestine slices for each group obtained with a magnification of $1000 \mathrm{X}$ are showed (b).

Fig. 5.Effects of riboflavin-producing LAB on cytokine levels in intestinal fluids of mice with TNBS-induced colitis. The concentration (pg mg ${ }^{-1}$ protein) of IL-10 (black), IL-17 (white), TNF$\alpha$ (light grey), IFN- $\gamma$ (white with diagonal lines), IL-6 (dark grey), IL-4 (dotted white) and IL-2 (white with horizontal lines) were measured in the large intestine contents of mice from each group. Results are expressed as means $(n=7$, except for the mock group $n=3) \pm$ SD. For each cytokine, different letters (a-c) statistically differ $(p<0.05)$.

This article is protected by copyright. All rights reserved. 


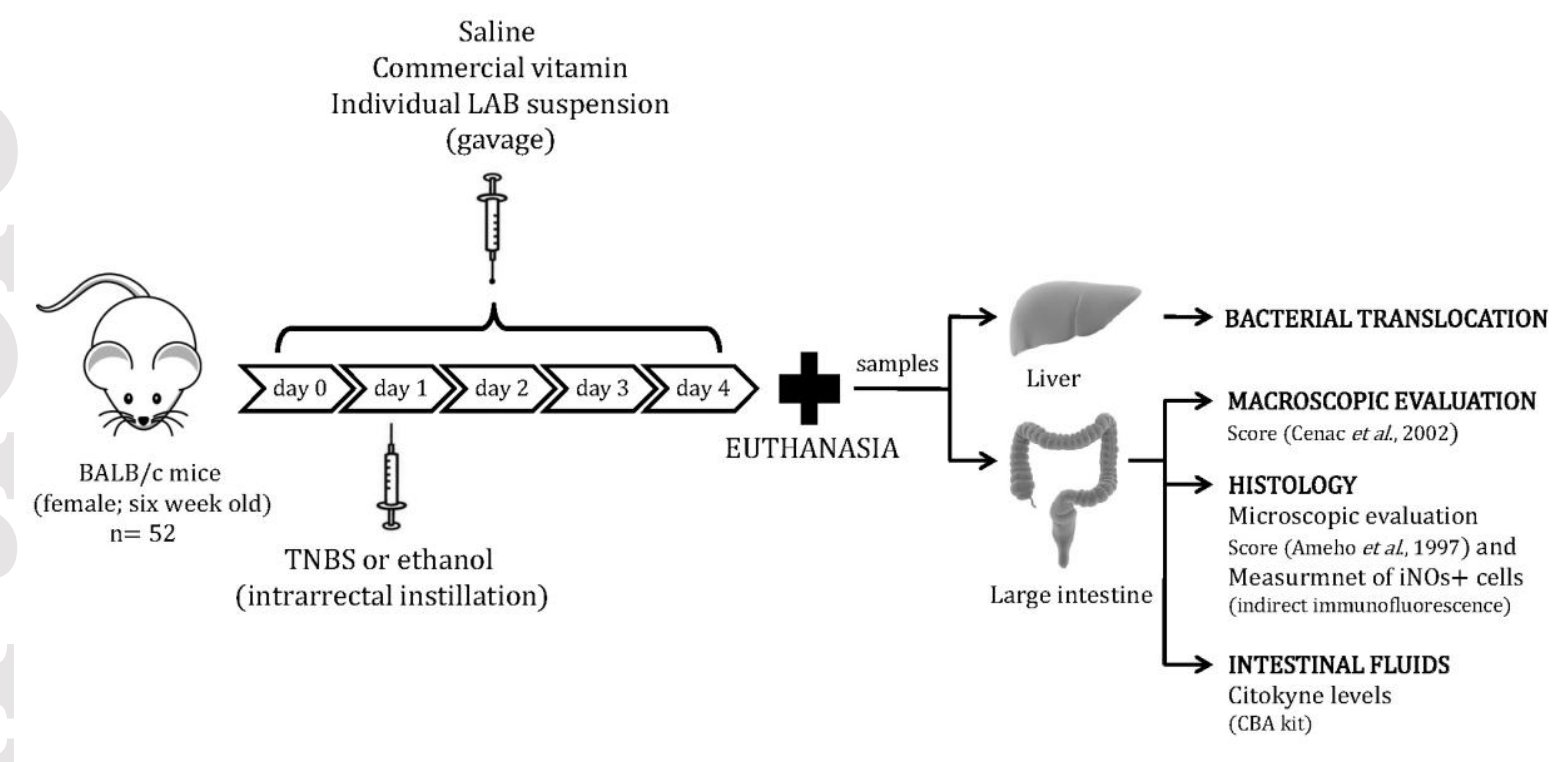

This article is protected by copyright. All rights reserved. 


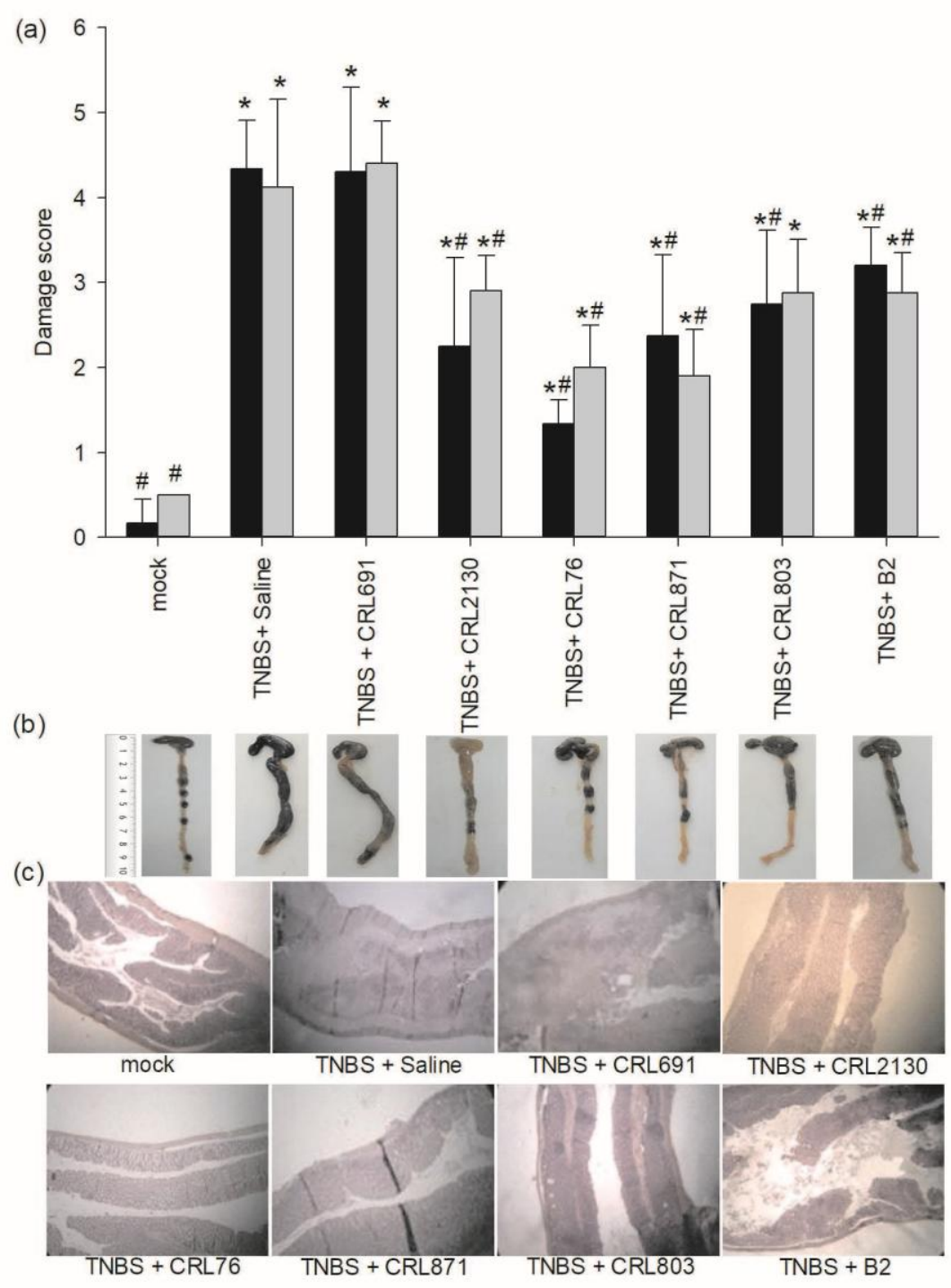

This article is protected by copyright. All rights reserved. 


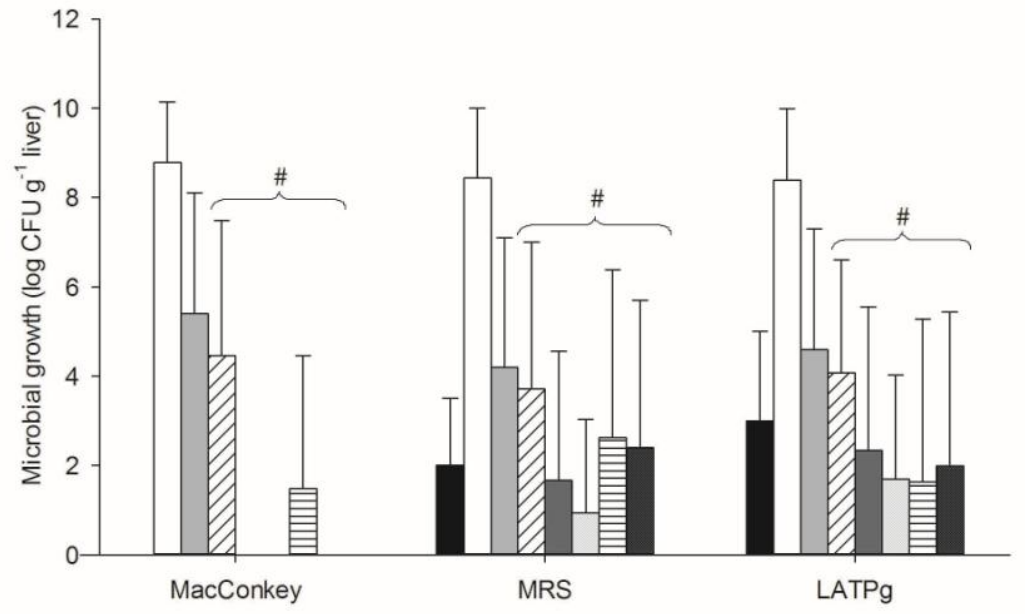

This article is protected by copyright. All rights reserved. 


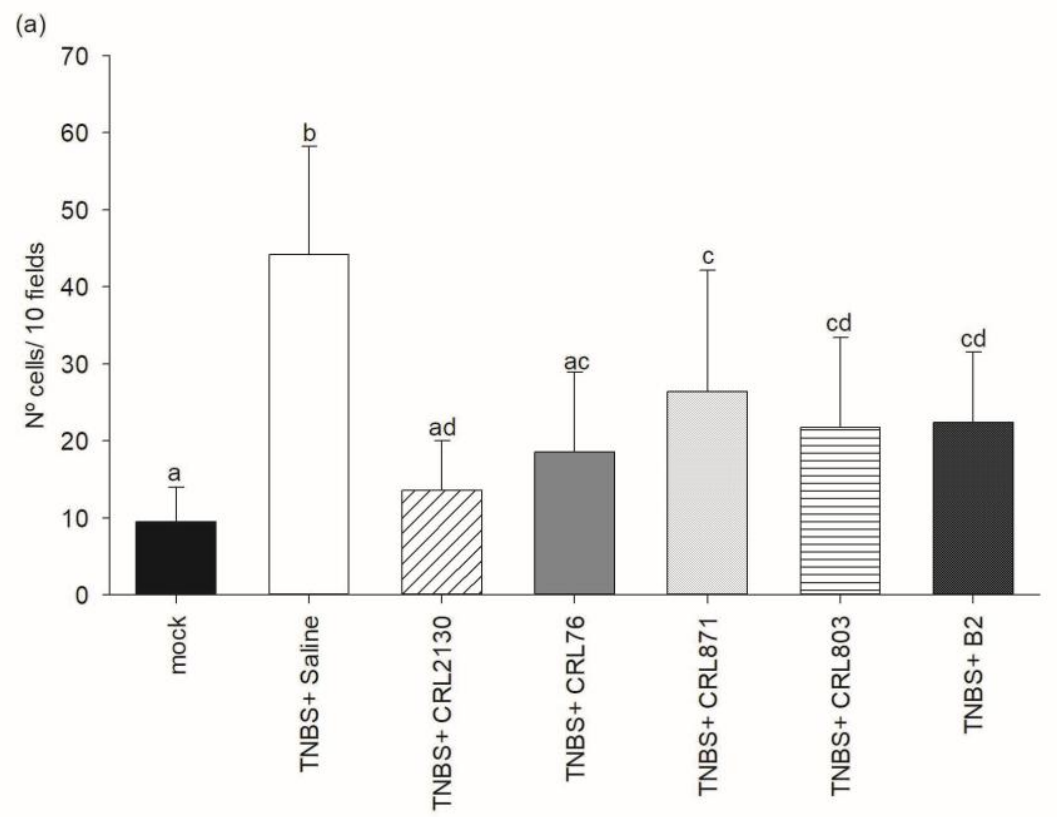

(b)
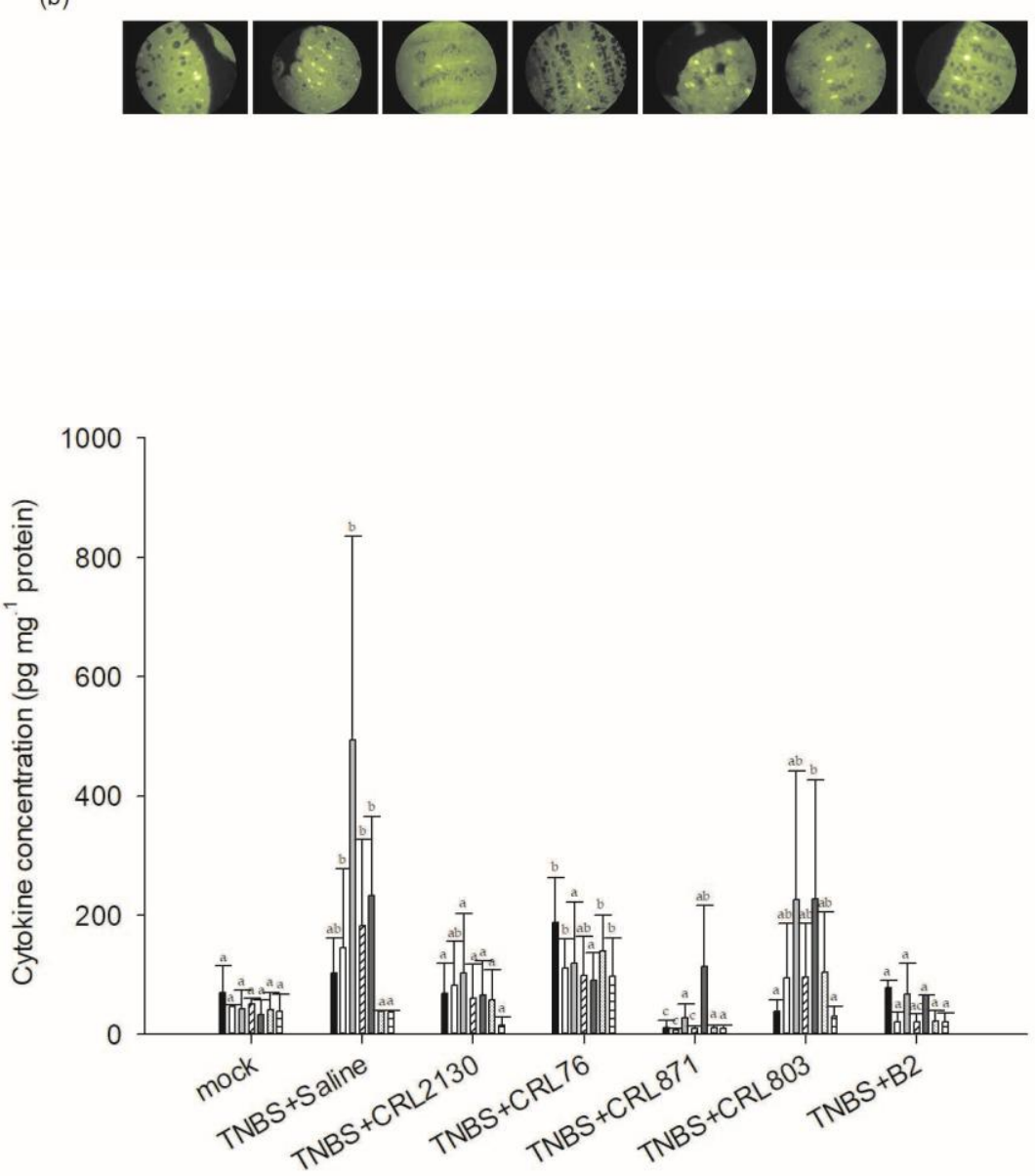

This article is protected by copyright. All rights reserved. 